Louisiana State University

LSU Digital Commons

$1-1-2009$

\title{
Diverse elevational diversity gradients in great smoky mountains national park, U.S.A.
}

\author{
Nathan J. Sanders \\ The University of Tennessee, Knoxville \\ Robert R. Dunn \\ NC State University \\ Matthew C. Fitzpatrick \\ The University of Tennessee, Knoxville \\ Christopher E. Carlton \\ Louisiana State University \\ Michael R. Pogue \\ Smithsonian National Museum of Natural History
}

See next page for additional authors

Follow this and additional works at: https://digitalcommons.Isu.edu/entomology_pubs

\section{Recommended Citation}

Sanders, N., Dunn, R., Fitzpatrick, M., Carlton, C., Pogue, M., Parker, C., \& Simons, T. (2009). Diverse elevational diversity gradients in great smoky mountains national park, U.S.A.. Data Mining for Global Trends in Mountain Biodiversity, 75-87. https://doi.org/10.1201/9781420083705

This Article is brought to you for free and open access by the Department of Entomology at LSU Digital Commons. It has been accepted for inclusion in Faculty Publications by an authorized administrator of LSU Digital Commons. For more information, please contact ir@lsu.edu. 


\section{Authors}

Nathan J. Sanders, Robert R. Dunn, Matthew C. Fitzpatrick, Christopher E. Carlton, Michael R. Pogue, Charles R. Parker, and Theodore R. Simons 
Winterthurerstr. 190

CH-8057 Zurich

http://www.zora.uzh.ch

Year: 2009

\title{
Are ridge habitats special sites for endemic plants in tropical montane rain forests? A case study of Pteridophytes in Ecuador
}

\author{
Kessler, M; Lehnert, M
}

Kessler, M; Lehnert, M (2009). Are ridge habitats special sites for endemic plants in tropical montane rain forests? A case study of Pteridophytes in Ecuador. Folia Geobotanica, 44(4):387-398.

Postprint available at:

http://www.zora.uzh.ch

Posted at the Zurich Open Repository and Archive, University of Zurich.

http://www.zora.uzh.ch

Originally published at:

Folia Geobotanica 2009, 44(4):387-398. 


\title{
Are ridge habitats special sites for endemic plants in tropical montane rain forests? A case study of Pteridophytes in Ecuador
}

\begin{abstract}
We addressed whether ridges, which are ecologically distinct from slopes, harbor specialized plant assemblages with a high representation of endemic species. We surveyed pteridophytes in 28 plots each of $400 \mathrm{~m} 2$ in ridge and slope forests at 2,430-2,660 $\mathrm{m}$ at three different localities in southeastern Ecuador. Data analysis was based on those 147 species with reliable determinations and excluded 14 undetermined species. Range sizes were expressed as the latitudinal distance between the northern- and southernmost collections, and species were then assigned to range-size quartiles, with the 1st quartile including the $25 \%$ most widespread species, etc. Differences in species richness per range-size quartile were determined using G-tests and differences in abundance using ANOVAs. The recorded 147 fern species were represented by 21,800 individuals, including 106 terrestrial (7,300 individuals) and 98 epiphytic species $(14,500)$. Ridges had fewer species than slopes, and there was no higher representation of localized species on ridges. Overall, widespread species were weakly $\left(\mathrm{R}^{2}=0.03\right)$ but significantly more abundant than localized species. Ridges had significantly higher abundances of terrestrial - but not of epiphytic - species compared to slopes, especially among the widespread species of the 1st range-size quartile. The contribution of ridge habitats to overall pteridophyte diversity and as habitats for endemics in our study region is low. Methodologically, the separation of species into range-size classes in an ecological study is novel and effective, as statistically significant patterns were found only for species belonging to the 1 st or 4 th quartiles.
\end{abstract}




\title{
Are Ridge Habitats Special Sites for Endemic Plants in Tropical Montane Rain Forests? A Case Study of Pteridophytes in Ecuador
}

\author{
Michael Kessler • Marcus Lehnert
}

(C) Institute of Botany, Academy of Sciences of the Czech Republic 2009

\begin{abstract}
We addressed whether ridges, which are ecologically distinct from slopes, harbor specialized plant assemblages with a high representation of endemic species. We surveyed pteridophytes in 28 plots each of $400 \mathrm{~m}^{2}$ in ridge and slope forests at 2,430-2,660 $\mathrm{m}$ at three different localities in southeastern Ecuador. Data analysis was based on those 147 species with reliable determinations and excluded 14 undetermined species. Range sizes were expressed as the latitudinal distance between the northern- and southernmost collections, and species were then assigned to range-size quartiles, with the 1 st quartile including the $25 \%$ most widespread species, etc. Differences in species richness per range-size quartile were determined using $G$-tests and differences in abundance using ANOVAs. The recorded 147 fern species were represented by 21,800 individuals, including 106 terrestrial $(7,300$ individuals) and 98 epiphytic species $(14,500)$. Ridges had fewer species than slopes, and there was no higher representation of localized species on ridges. Overall, widespread species were weakly $\left(R^{2}=0.03\right)$ but significantly more abundant than localized species. Ridges had significantly higher abundances of terrestrial - but not of epiphytic - species compared to slopes, especially among the widespread species of the 1st range-size quartile. The contribution of ridge habitats to overall pteridophyte diversity and as habitats for endemics in our study region is low.
\end{abstract}

M. Kessler · M. Lehnert

Albrecht-von-Haller-Institut für Pflanzenwissenschaften, Abteilung Systematische Botanik, Untere Karspüle 2, 37073 Göttingen, Germany

Present Address:

M. Kessler

Systematic Botany, University of Zürich, Zollikerstrasse 107, CH-8008 Zürich, Switzerland

Present Address:

M. Lehnert $(\bowtie)$

Staatliches Museum für Naturkunde Stuttgart, Am Löwentor, Rosenstein 1, 70191 Stuttgart, Germany e-mail: lehnert.smns@naturkundemuseum-bw.de 
Methodologically, the separation of species into range-size classes in an ecological study is novel and effective, as statistically significant patterns were found only for species belonging to the 1 st or 4 th quartiles.

Keywords Andes $\cdot$ Endemism $\cdot$ Ferns $\cdot$ Range size $\cdot$ Slopes

Plant nomenclature Smith (1983); Stolze (1986); Tryon (1986); Øllgaard (1988); Tryon and Stolze (1989-1994); Stolze et al. (1994); Øllgaard et al. (2001)

\section{Introduction}

Mountain forest ecosystems are characterized by a high diversity of environmental conditions and habitats. In addition to typical (zonal) vegetation on slopes of medium inclination, azonal vegetation types develop on very steep slopes, flat valley bottoms, and on ridges. The latter are usually characterized by special abiotic conditions, including higher exposure to winds, stronger fluctuations in air humidity, and often leached, acidic, and nutrient-poor soils (Hetsch and Hoheisel 1976; Grubb 1977; Tanner et al. 1998; Proctor et al. 1999). In cloud forests, the stronger winds on ridges result in a higher deposition of mist water and dissolved nutrients (e.g., Clark et al. 1998). Accordingly, the vegetation on ridges is typically low and open compared to adjacent slopes (Proctor et al. 1999). This difference in vegetation structure in turn influences the environmental conditions within the ridge forests, which typically have higher light availability near ground level and lower, more variable air humidity (J. Kluge and M. Kessler, unpubl. data). In combination, these environmental differences determine floristic changes in the vegetation, and ridge forests typically are composed of fewer species than zonal forests (Tanner 1977).

Despite these special features of tropical ridge forests, little research has so far focused on their contribution to plant diversity and even less on the representation of endemic plants in these habitats. Ridge forests are localized habitats of restricted distribution. Accordingly, species specialized to occur on ridges will have scattered populations of limited size, which can lead to population differentiation and the development of endemic taxa (Cowling et al. 1992; Brown et al. 1996; Gaston 1996; Kessler 2002a, b). Ridges, however, are environmentally extreme habitats. Endemic plant species have often been considered to be competitively inferior to widespread species (Griggs 1940; Kruckeberg and Rabinowitz 1985; Major 1988; Kunin and Gaston 1993; Walck et al. 1999; Lavergne et al. 2005) and this may limit their occurrence in stressful situations. Accordingly, one may expect endemic plant species to be either especially abundant or rare on ridges.

Among pteridophytes (lycophytes and ferns), which are one of the most abundant and species-rich terrestrial and epiphytic herbaceous plant groups in tropical montane rain forests, Kessler (2001) found $10 \%-20 \%$ lower species richness on ridges in a very wet montane region of central Bolivia, and very few species restricted to ridge forests. However, epiphytic ferns on ridges on average had smaller range sizes, i.e., higher levels of endemism, than in adjacent slope forests. Among terrestrials, the opposite pattern was found. This suggests that at least for epiphytic 
pteridophytes, ridge forests are an important habitat for endemic species. A more recent study on the Caribbean slope of Costa Rica found a similar decrease of species richness on ridges and few species restricted to them, but the proportion of endemics remained constant relative to slope forests (J. Kluge and M. Kessler, unpubl. data). These inconsistent results, with high endemism of epiphytes at one site and average endemism at the other, call for additional studies on this topic. In the present study, we analyzed patterns of fern richness and endemism at three montane forest sites in southeastern Ecuador. This area is particularly suitable for this kind of study because the region is well known for its high levels of biological endemism (Lozano et al. 2003) and the presence of extensive areas of stunted ridge forests (Gradstein et al. 2008).

\section{Material and Methods}

\section{Study Sites}

We studied upper montane ridge and slope forests in three different localities: Reserva Biológica San Francisco (RBSF), below the mountain pass El Tiro, and Cerro Tapichalaca Reserve (Fig. 1). Ranging between 1,800 m and 3,140 m, RBSF preserves some one thousand hectares of humid evergreen mountain rainforests and páramo vegetation (Beck and Müller-Hohenstein 2001). The high relief energy with

Fig. 1 Map of the study region in Ecuador showing the location of the study sites. RBSF - Reserva Biológica San Francisco

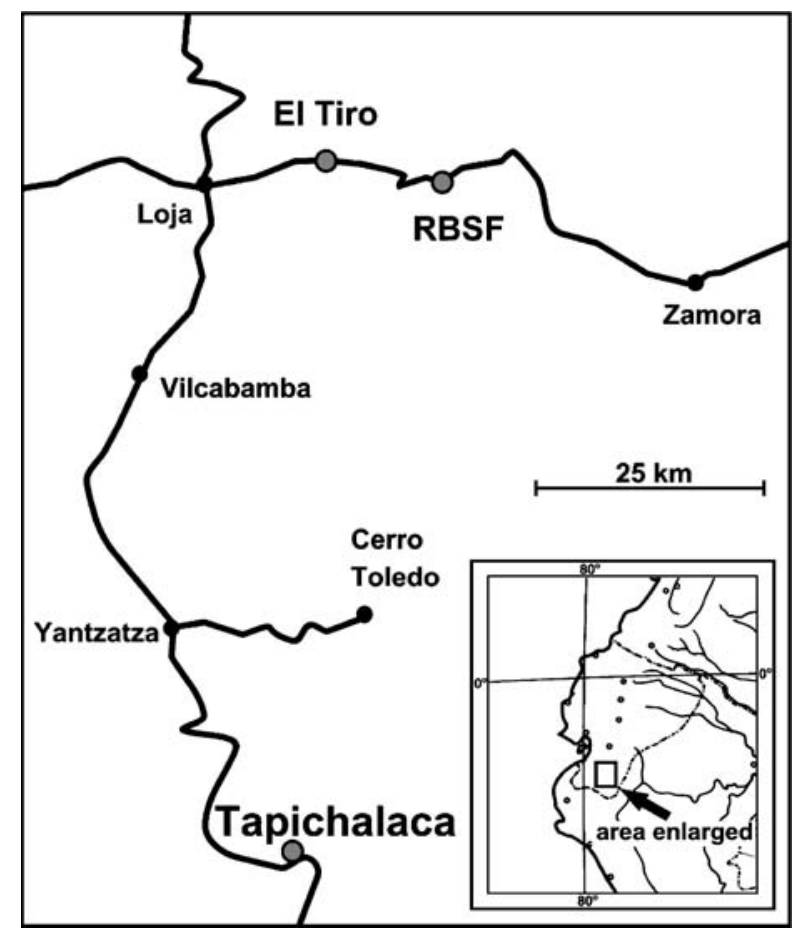


steep and unstable slopes, causing frequent occurrence of landslides, is a characteristic feature of the reserve. Geologically the area is made up of Paleozoic, weakly metamorphic rocks consisting of meta-siltstones, sandstones, and phyllites with some quartz veins, dated to the Devonian-Permian age (Litherland et al. 1994). Consequently, soils are poor in nutrients (Wilcke et al. 2001). Towards higher elevations soils become less well developed, accumulation of organic material increases, and hygrophytic soil properties become prominent (Schrumpf et al. 2001). Mean annual precipitation is about $5,300 \mathrm{~mm}$, with no month with less than $100 \mathrm{~mm}$, and April to July being the wettest months (>600 mm) (Gradstein et al. 2008).

Mountain pass El Tiro $\left(79^{\circ} 08^{\prime} \mathrm{W}, 03^{\circ} 59^{\prime} \mathrm{S}\right)$ is situated at ca. 2,800 $\mathrm{m}$ along the Loja-Zamora road, $15 \mathrm{~km} \mathrm{~W}$ of the RBSF and on the border of Loja and ZamoraChinchipe provinces, on the crest of the cordillera. The pass separates the dry interandean Río Zamora valley from the humid Rio San Francisco Valley leading towards the Amazonian lowland. Our study site was located some 200-450 m below the actual pass towards the east, in an area of very rugged topography with many small ravines and ridges overgrown by a low, shrubby cloud forest. Rocks at El Tiro belong to the same geological formation as in RBSF. Mean annual precipitation is about $3,100 \mathrm{~mm}$.

Cerro Tapichalaca Reserve $\left(79^{\circ} 07^{\prime} \mathrm{W}, 04^{\circ} 29^{\prime} \mathrm{S}\right)$ is situated at ca. 2,000-3,400 m along the Loja-Zumba road in the Cordillera Real, ca. $90 \mathrm{~km} \mathrm{~S}$ of the town of Loja and just $S$ of Podocarpus National Park (Fig. 1). The area separates the dry interandean Río Solano valley from the wet Río Mayo valley oriented towards the Amazonian lowland and consists of very wet montane cloud forest and páramo (Simpson 2004). Geologically, the Tapichalaca Reserve is made up of Mesozoic ortho-gneisses from the late Triassic age (Litherland et al. 1994). Mean annual precipitation is about $3,900 \mathrm{~mm}$.

\section{Field Methods}

We established 28 plots of $20 \mathrm{~m} \times 20 \mathrm{~m}$ in size or an equivalent of $400 \mathrm{~m}^{2}$ if the terrain did not allow square plots to maintain a homogeneous forest structure, especially on narrow ridges. All plots were located at elevations of 2,430-2,660 m to minimize the impact of elevation. In each study area, we placed a number of plots specifically on ridges and on adjacent slopes, with the number of plots varying due to accessibility in the difficult terrain. At ECSF six plots were on ridges and four on slopes, and at El Tiro three were on ridges and six on slopes, whereas at Tapichalaca three were on ridges and six on slopes. At all study sites, tree height varied from $3 \mathrm{~m}$ to $12 \mathrm{~m}$ on ridges and from $5 \mathrm{~m}$ to $20 \mathrm{~m}$ on slopes, and the number of trees $>10 \mathrm{~cm}$ diameter at breast height varied from 6-12 on ridges to 15-24 on slopes (Gradstein et al. 2008).

Pteridophytes were recorded as distinguishable morphospecies in the field. Abundance and life form (epiphytic; terrestrial including saxicolous) were noted for all species in each plot. Each fertile or full-grown plant was counted as one individual; in the case of clonal plants, we estimated the number of clones based on their spatial position. Epiphytes were counted both from the ground with binoculars and by climbing selected trees. At least one voucher per morphospecies was 
collected and dried for later identification. Duplicates are deposited in herbaria in the following priority: Quito, Universidad Católica (QCA), Berkeley (UC), Loja (LOJA), Göttingen (GOET), Aarhus (AAU), and the herbarium at the Estación Cientifica San Francisco (ECSF); one set of Elaphoglossum specimens was sent to New York (NY), and one set of Polystichum is at Vermont (VT). Determinations were done largely by ML at the Herbarium AAU (Apr 2004, Feb 2005); complicated groups were dealt with by specialists.

\section{Data Analysis}

For the data analysis we only considered those 147 species with reliable determinations and excluded those 14 species for which no names and hence no range sizes could be obtained. Range sizes for each species were expressed as the latitudinal distance between the northern- and southernmost collections, based on the holdings of the herbaria LPB, MO, NY, QCA, UC, and US as well as relevant literature, especially Tryon and Stolze (1989-1994), Moran and Riba (1995), Mickel and Smith (2004), and Kessler and Smith (in prep.). Because all our study species are montane, and because the Andes and Mesoamerican mountain ranges extend from north to south, latitudinal range is a good measure of overall range size (Kessler 2002a). Species were then assigned to range-size quartiles, with the 1st quartile including the $25 \%$ most widespread species (latitudinal ranges 35-53 degrees), the 2 nd quartile species with ranges of 26-34 degrees, the 3 rd one species with ranges of 14-25 degrees, and the 4 th one the endemic species with ranges of 1-13 degrees.

Abundance of each species was calculated as the mean number of individuals per plot for each species. Because the abundance distribution was uneven, with $10.2 \%$ of the species accounting for $50.5 \%$ of all individuals, the abundance distributions were expressed as the abundance rank order. In this way, the abundance data approached normality and parametric statistics could be used. Differences in species richness per range-size quartile were determined using $G$-tests, and differences in the abundances of the species in the range-size quartiles through ANOVAs. These tests were first conducted for all classes compared in a given test (e.g., range-size quartiles, localities, habitats) and only when the overall test revealed a significant pattern did we conduct post-hoc tests to determine which of the classes differed from each other. All statistical analyses were carried out with Systat 11 (SYSTAT 2004).

\section{Results}

In total, we recorded 147 fern species represented by ca. 21,800 individuals. Among these, 106 species with ca. 7,300 individuals grew terrestrially and 98 species with ca. 14,500 individuals epiphytically. Accordingly, 57 species were found to be both terrestrials and epiphytes. At the different study sites, we found 96 species at the RBSF (46 on ridges, 75 on slopes), 89 at El Tiro (42 on ridges, 85 on slopes), and 97 species at Tapichalaca (54 on ridges, 85 on slopes). The numbers of individuals per species were highly unevenly distributed (Fig. 2a). The three small, epiphytic grammitid ferns Melpomene wolfii (1,285 individuals), Grammitis bryophila $(1,217)$ 


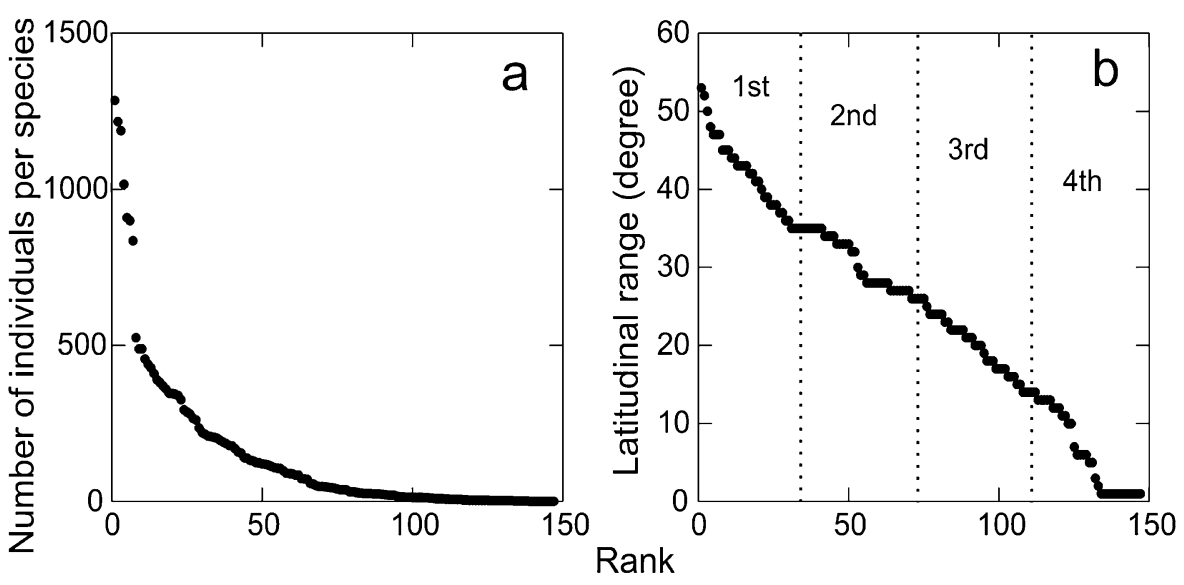

Fig. 2 Rank-abundance (a) and rank-range size (b) plots for all 147 species included in this study. The stippled lines denote the range-size quartiles

and Terpsichore lanigera $(1,188)$ had the highest numbers. The most abundant terrestrial species was the filmy fern Trichomanes dactylites (909 individuals), followed by the tree ferns Cyathea peladensis (835) and Cyathea meridensis (428). At the opposite end of the scale, nine species were only represented by a single individual, five species by two individuals, and eight species by three individuals.

Latitudinal amplitudes showed a more gradual distribution (Fig. 2b). Two species of Asplenium, A. serra and A. auriculatum, had the widest ranges, covering 53 and 52 degrees, respectively, followed by Hymenophyllum polyanthos with 50 degrees. In contrast, 14 species were localized endemics with ranges of only 1 degree, and a further nine species had ranges spanning 2-7 degrees.

Looking at species richness per range-size-quartile at the three study sites, the endemics of the 4th quartile had somewhat fewer species per site than the other three quartiles, but this difference was not significant at any site ( $G$-tests; RBSF: $G=1.69$, $P=0.65$; El Tiro: $G=3.55, P=0.35$; Tapichalaca: $G=1.58, P=0.67$ ) (Fig. 3). However, Tapichalaca had significantly more species in the 1st quartile (widespread species) than in the other quartiles ( $G$-test, $G=7.93, P=0.046)$. It also had more species in the 1 st quartile than either the RBSF ( $G$-test, $G=9.63, P=0.03$ ) or El Tiro ( $G$-test, $G=7.32, P=0.052$ ), whereas there was no significant difference between the RBSF and El Tiro ( $G$-test, $G=0.86, P=0.71)$. This difference was not so evident when terrestrial and epiphytic species were analyzed separately, with the $P$-values of comparisons between Tapichalaca, and the RBSF and El Tiro ranging between 0.17 and 0.27 ( $G$-tests).

Comparing the species richness of the four range-size classes on ridges versus slopes showed that ridges had fewer species than slopes. However, these differences were not significant either for all sites combined ( $G$-tests; all species: $G=4.08$, $P=0.29$; epiphytes: $G=2.74, P=0.42$; terrestrials: $G=3.95, P=0.31$ ) or when sites were analyzed separately, except at El Tiro, where ridges had significantly fewer species than slopes in both the 1 st and 4th quartiles ( $G$-test, $G=12.52, P=0.008)$ (Fig. 3).

Comparing the species richness of the range-size classes between terrestrial and epiphytic species revealed no significant differences either across all sites and 
Fig. 3 Species richness per range-size quartile (black - 1st quartile, widespread species; dark gray - 2nd; light gray $3 \mathrm{rd}$; white -4 th, endemics) and habitat ( $\mathrm{a}$ - all; $\mathrm{r}$ - ridges; $\mathrm{s}$ slopes) for three study sites

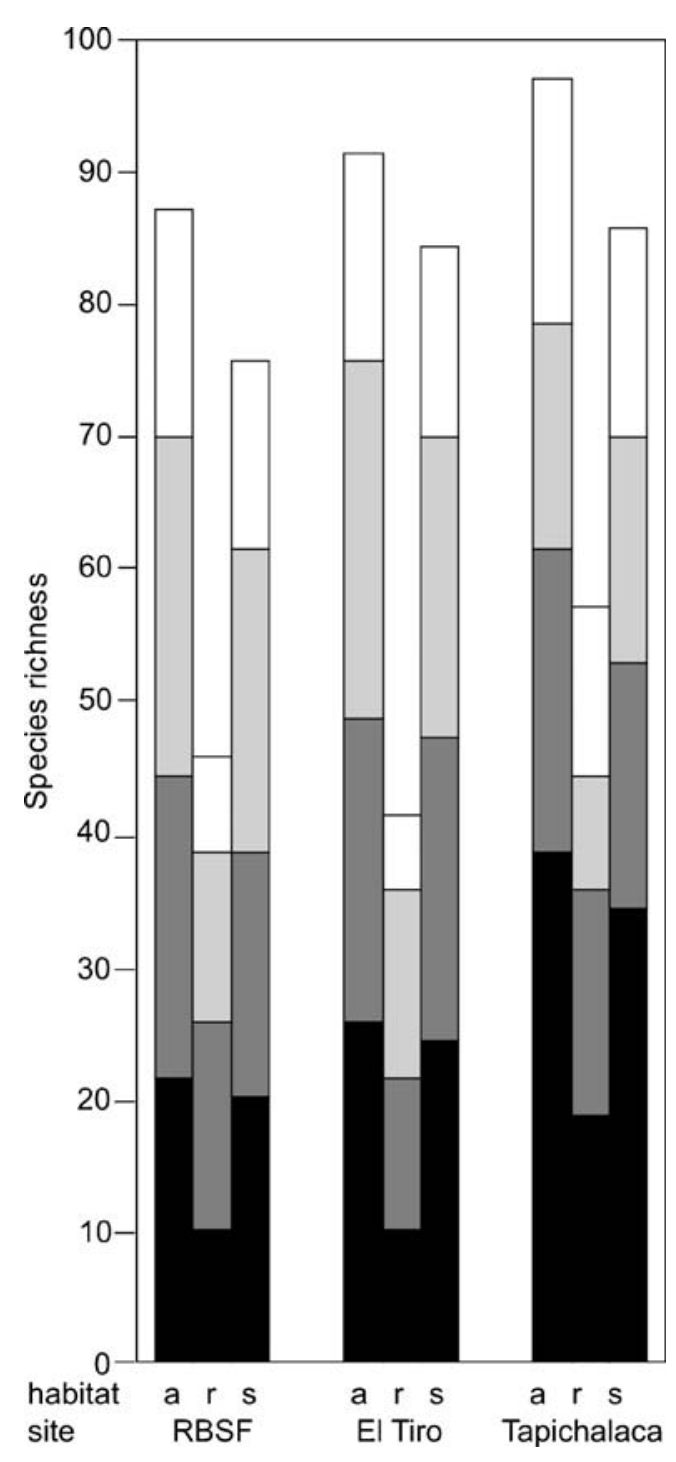

habitats ( $G$-test; $G=0.86, P=0.71$ ) or separately for sites and/or habitats (individual results not shown).

Regarding abundance of the species, there was a weak, but significant relationship between latitudinal amplitude and ranked species abundance (linear regression, $\left.R^{2}=0.027, P=0.047\right)$. In particular, the endemic species of the 4 th quartile had significantly lower abundances than the other three quartiles (oneway two-tailed ANOVA, $F_{3,147}=3.310, P=0.022$ ) (Fig. 4). This trend was also visually evident when the life forms were analyzed separately, but was not significant (one-way two-tailed ANOVAs, epiphytes: $F_{3,98}=2.037, P=0.115$; terrestrials: $\left.F_{3,106}=1.220, P=0.306\right)$. 
Fig. 4 Ranked species abundance per range-size quartile among all 147 species included in this study. Boxes are notched at the median, return to full width at their upper and lower confidence interval values, and have their limits at their standard deviations; lines show double standard deviations

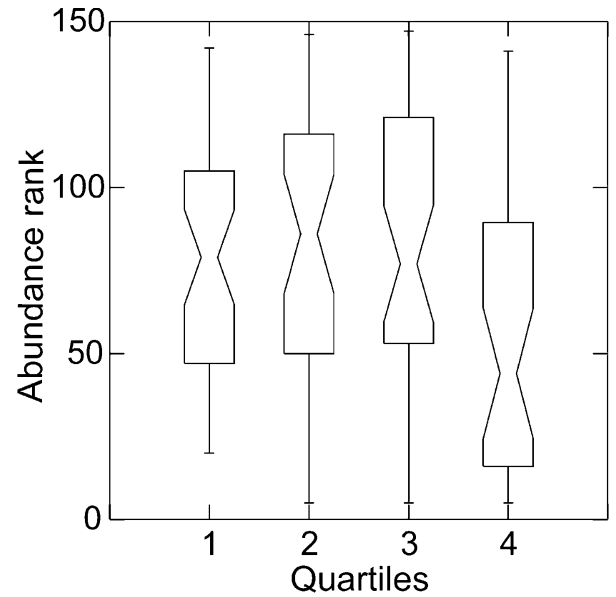

The distribution of ranked abundance among the four range-size classes did not differ between epiphytic and terrestrial species (one-way two-tailed ANOVA, $F_{1,198}=0.920$, $P=0.34$ ). Comparing the three study sites, there were no significant differences in the abundances of species per quartile for all (one-way two-tailed ANOVA, $F_{2,296}=0.729$, $P=0.62$ ), terrestrial (one-way two-tailed ANOVA, $F_{2,177}=1.458, P=0.24$ ), or epiphytic species (one-way two-tailed ANOVA, $F_{2,166}=0.146, P=0.86$ ).

Comparing ridges and slopes, ridges generally had much higher species abundances than slopes among terrestrial species (one-way two-tailed ANOVA, $F_{1,170}=10.038, P=0.002$ ) but not among epiphytic species (one-way two-tailed ANOVA, $\left.F_{1,182}=0.636, P=0.43\right)$. All species combined hinted of the pattern of the terrestrial species, but not significantly so (one-way two-tailed ANOVA, $F_{1,147}=1.403, P=0.24$ ), certainly due to the leveling effect of the epiphytic species. However, there were no significant differences between the range-size quartiles within any given habitat, either for all species combined (one-way two-tailed ANOVA, $F_{1,147}=1.161, P=0.33$ ), for terrestrials (one-way two-tailed ANOVA, $F_{1,70}=2.200, P=0.09$ ) or epiphytes (one-way two-tailed ANOVA, $F_{1,82}=0.245$, $P=0.87$ ) analyzed separately. Interactions between quartiles and habitat were not significant either (data not shown). However, when the sites were analyzed separately, terrestrial species of the 1 st quartile were significantly less abundant on slopes compared to ridges at all three sites (one-way two-tailed ANOVAs; RBSF: $F_{3,50}=2.783, P=0.044$; El Tiro: $F_{3,61}=2.830, P=0.045$; Tapichalaca: $F_{3,66}=2.953$, $P=0.038$ ) (Fig. 5). We could not detect any taxonomic or ecological difference between the narrow-ranged terrestrial species on ridges compared to those on slopes, with tree ferns and various Polypodiaceae being the dominant taxa in all cases.

\section{Discussion}

The starting point of our study was the question whether ridge habitats, with their strikingly different environmental conditions, harbor specialized pteridophyte assemblages with an overrepresentation of endemic species. We found that ridges 
Fig. 5 Relative species abundances per quartile comparing ridge habitats (left boxes for each quartile) and slope habitats (right boxes). To exclude the overall differences in abundance between ridge and slope habitats, for this graph relative abundance was used with $100 \%$ corresponding to the mean value within each habitat. Boxes are notched at the median, return to full width at their upper and lower confidence interval values, and have their limits at their standard deviations; lines show double standard deviations, stars outliers

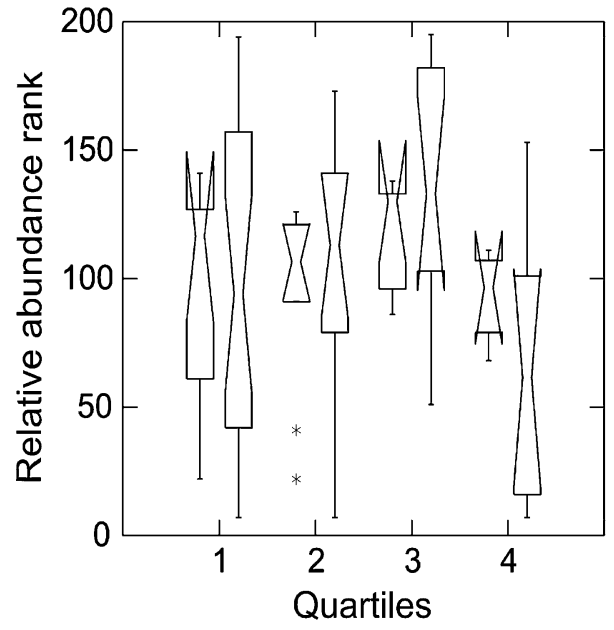

in the area of the Podocarpus National Park had fewer species than slopes (Fig. 3) and that this reduction of species richness affected species belonging to all four range-size quartiles in a similar way. Our study therefore confirms the pattern found in Costa Rica (J. Kluge and M. Kessler, unpubl. data), and contrasts with the observations of Kessler (2001) who found a relatively higher representation of endemic pteridophytes on ridges compared to adjacent slopes in Bolivia. The latter pattern was also documented on Cordillera Mosetenes in Bolivia, where range sizes of pteridophytes on ridges at 1,500-1,600 m averaged ca. $25 \%$ smaller than in adjacent slope forests at 1,400-1,500 m (M. Kessler, I. Jiménez and T. Krömer, unpubl. data). Apparently, ridge habitats are more suitable for range-restricted pteridophyte species in some situations, whereas in others this is not the case. Whether this discrepancy is a regional phenomenon or whether it varies on a more local basis cannot yet be answered with the geographically limited data at hand. Importantly, however, none of the four studies found a lower representation of endemics on ridges, showing that the presumably stressful abiotic conditions on ridges do not affect range-restricted species more strongly than widespread taxa.

Regarding the abundances of species, ridges had significantly higher abundances of terrestrial species compared to slopes, certainly as a result of the low, open canopy structure that allows high light levels to reach ground level, leading to the development of a dense herbaceous layer in which pteridophytes feature prominently. In contrast, the tall, dark slope forests have a sparse herb layer with scattered pteridophyte individuals. Interestingly, this effect appeared to be most pronounced among the widespread species of the 1 st quartile, indicating that they were most sensitive to the ecological differences between slopes and ridges. Alternatively, one may argue that endemic terrestrial species (4th quartile) were less abundant on slopes than more widespread species. The positive relationship of range size and local abundance is a common pattern in community ecology (Gaston et al. 1997, 1998), although it is often rather weak (Gaston 1996), as also found in our study. In our case this pattern was mainly due to the low abundance of endemic species on slope habitats. Endemic plant species have often been considered to be competitively 
inferior to widespread taxa (Griggs 1940; Kruckeberg and Rabinowitz 1985; Major 1988; Kunin and Gaston 1993; Walck et al. 1999; Lavergne et al. 2005) and it has been argued that this low competitive ability might be what limits their capability of establishing new populations beyond their existing ranges, thereby limiting their range sizes (Kessler 2002a, b). If this reasoning is followed, then a paradoxical situation emerges for the evaluation of the stressfulness of ridge habitats: they harbor fewer species suggesting that they are abiotically stressful habitats, but they also have a higher abundance of terrestrial species, especially presumably competitively inferior species with restricted ranges, suggesting that they are biotically less stressful habitats. Apparently, abiotic stress influences the species richness and the abundance of species in different ways.

Contrary to terrestrial species, epiphytes did not show differences in abundance between slopes and ridges, probably due to the greater ecological similarity of the canopy habitat between ridges and slopes relative to the terrestrial environment. For epiphytes, the main habitat differentiation takes place between the different parts of the host trees (Johansson 1974; Krömer and Gradstein 2003; Krömer et al. 2005). Therefore, the general site conditions are less important than the microclimatic conditions at the actual growth locations of the epiphytic species.

In conclusion, pteridophyte assemblages on ridges in our study area had a higher abundance of terrestrial species, especially those with restricted ranges, and with no conspicuous differences at the level of epiphytes. Accordingly, the contribution of ridge habitats to overall pteridophyte diversity in a given region such as the Podocarpus National Park is low. The major contribution, if any, might be that some range-restricted species have their main populations on ridges, even if they also occur on slopes. Conceivably, the latter populations might not be self-sustaining, but represent sink populations dependent on ridge populations for continued survival. The documentation of such source-sink relationships requires detailed, long-term data on population dynamics greatly exceeding the possibilities of a study like ours (Eriksson 1996).

A final, striking pattern was that at Tapichalaca the 1st quartile (with the widespread species) was significantly more species rich than the other quartiles as well as the 1st quartile at the other two study sites. A possible interpretation of this pattern involves the degree of human influence at the three study sites. Tapichalaca appears to have been subject to stronger human disturbance than the other two sites (pers. observation). It is a young reserve established in 2001 and was acquired from local farmers who selectively logged the forest in the past. It directly borders longused farmland and meadows so there is still some impact of straying cattle in the reserve itself and some of our study plots that were placed close to the forest margin showed influence of cattle and logging. Widespread plant species are known to often fare better in strongly disturbed ecosystems than endemics (Brown 1984) and this may have caused the observed increase in species number and abundance at Tapichalaca compared to the other two sites, where human impact is generally lower.

To add a comment on methodology, this is only the second ecological study using range quartiles at a local scale to apply the subdivision of range-sizes of species within assemblages, compared to the regional to global scale at which this approach has previously been used (e.g., Jetz and Rahbek 2002; Kreft et al. 2006). Our results show that the subdivision of a species pool into range-size classes (which may be 
quartiles or any other meaningful categories) can be successfully applied to the local scale and that relative to previous methods, where range-size measures were applied across all species, e.g., by averaging their range sizes (Usher 1986; Kessler 2002a, b), the distinction between the range-size classes provides more detailed information. In our study, statistically significant patterns were found only for species belonging to the 1st or 4th quartiles, suggesting that half of all species with intermediate range sizes are not strongly affected by the studied habitat conditions, and that only the species with the most extreme ranges, be it large or small, show detectable patterns.

Acknowledgements We thank Nicki Mandl for collaboration in the field, Dave S. Barrington, Robbin C. Moran, Benjamin Øllgaard and Alan R. Smith for help with species determinations, and three anonymous reviewers for comments on the manuscript. This study was funded by Deutsche Forschungsgemeinschaft (DFG grant GR 1588/7).

\section{References}

Beck E, Müller-Hohenstein K (2001) Analysis of undisturbed and disturbed tropical mountain forest ecosystems in Southern Ecuador. Die Erde 132:1-8

Brown JH (1984) On the relationship between abundance and distribution of species. Amer Naturalist 124:255-279

Brown JH, Stevens GC, Kaufmann DM (1996) The geographic range: Size, shape, boundaries, and internal structure. Annual Rev Ecol Syst 27:597-623

Clark KL, Nadkarni N, Schaefer D, Gholz HL (1998) Atmospheric deposition and net retention of ions by the canopy in a tropical montane forest, Monteverde, Costa Rica. J Trop Ecol 14:27-45

Cowling RM, Holmes PM, Rebelo AG (1992) Plant diversity and endemism. In Cowling RM et al. (eds) The ecology of fynbos. Oxford University Press, Cape Town, pp 62-112

Eriksson O (1996) Regional dynamics of plants: a review of evidence for remnant, source-sink and metapopulations. Oikos 77:248-258

Gaston KJ (1996) The multiple forms of the interspecific abundance-distribution relationship. Oikos 75:211-220

Gaston KJ, Blackburn TM, Lawton JH (1997) Interpecific abundance-range relationships: an appraisal of mechanisms. J Anim Ecol 66:579-601

Gaston KJ, Blackburn TM, Lawton JH (1998) Aggregation and the interspecific abundance-occupancy relationship. J Anim Ecol 67:995-999

Gradstein SR, Kessler M, Lehnert M, Abiy M, Mandl N, Makeschin F, Richter M (2008) Vegetation, climate and soil of the unique Purdiaea forest of southern Ecuador. Ecotropica 14:15-26

Griggs RF (1940) The ecology of rare plants. Bull Torrey Bot Club 67:575-594

Grubb PJ (1977) Control of forest growth and distribution on wet tropical mountains: With special reference to mineral nutrition. Annual Rev Ecol Syst 8:83-107

Hetsch W, Hoheisel H (1976) Standorts- und Vegetationsgliederung in einem tropischen Nebelwald. Allg Forst-Jagd-Zeitung 147:200-209

Jetz W, Rahbek C (2002) Geographic range size and determinants of avian species richness. Science 297:1548-1551

Johansson DR (1974) Ecology of vascular epiphytes in West African rain forest. Acta Phytogeogr Suec 59:1-136

Kessler M (2001) Patterns of diversity and range size of selected plant groups along an elevational transect in the Bolivian Andes. Biodivers \& Conservation 10:1897-1920

Kessler M (2002a) Range size and its ecological correlates among the pteridophytes of Carrasco National Park, Bolivia. Global Ecol Biogeogr 11:89-102

Kessler M (2002b) Environmental patterns and ecological correlates of range-size among bromeliad communities of Andean forests in Bolivia. Bot Rev 68:100-127

Kreft H, Sommer JH, Barthlott W (2006) The significance of geographic range size for spatial diversity patterns in Neotropical palms. Ecography 29:21-30

Krömer T, Gradstein SR (2003) Species richness of vascular epiphytes in two primary forests and fallows in the Bolivian Andes. Selbyana 24:190-195 
Krömer T, Kessler M, Gradstein SR, Acebey A (2005) Diversity patterns of vascular epiphytes along an elevational gradient in the Andes. J Biogeogr 32:1799-1810

Kruckeberg AR, Rabinowitz D (1985) Biological aspects of endemism in higher plants. Annual Rev Ecol Syst 16:447-479

Kunin WE, Gaston KJ (1993) The biology of rarity: patterns, causes, and consequences. Trends Ecol Evol 8:298-301

Lavergne S, Thuiller W, Molina J, Debussche M (2005) Environmental and human factors influencing rare plant occurrence, extinction and persistence: a 115-year study in the Mediterranean region. J Biogeogr 32:799-811

Litherland M, Aspen JA, Jemielita RA (1994) The metamorphic belts of Ecuador. Overseas Mem Brit Geol Surv 11:1-147

Lozano P, Delgado T, Aguirre Z (2003) Estado actual de la flora endémica exclusiva y su distribución en el occidente del Parque Nacional Podocarpus. Funbotanica, Loja, Ecuador

Major J (1988) Endemism: a botanical perspective. In Myers AA, Giller PS (eds) Analytical biogeography. An integrated approach to the study of animal and plant distributions. Chapman and Hall, New York, pp 117-146

Mickel JT, Smith AR (2004) The pteridophytes of Mexico. Mem New York Bot Gard 88:1-1054

Moran RC, Riba R (1995) Flora Mesoamericana 1. Psilotaceae a Salviniaceae. Universidad Nacional Autónoma de Mexico, Mexico D.F.

Øllgaard B (1988) Flora of Ecuador 1. Lycopodiaceae. Dept. of Botany, Göteborg University, Göteborg

Øllgaard B, Tuomisto H, Moran RC, Østergaard Andersen E (2001) Flora of Ecuador 6. Ophioglossaceae10. Gleicheniaceae. Dept of Botany, Göteborg University, Göteborg

Proctor J, Bruijnzeel LA, Baker AJM (1999) What causes the vegetation types on Mount Bloomfield, a coastal tropical mountain of the western Philippines? Global Ecol Biogeogr 8:347-354

Schrumpf M, Guggenberger G, Valarezo C, Zech W (2001) Tropical montane rain forest soils. Development and nutrient status along an altitudinal gradient in the Southern Ecuadorian Andes. Die Erde 132:43-59

Simpson N (2004) Saving threatened plants and birds in the Andes of Ecuador. Pl Talk 37:17-21

Smith AR (1983) Flora of Ecuador 14 (4). Polypodiaceae-Thelypteridoideae. Dept of Botany, Göteborg University, Göteborg

Stolze RG (1986) Flora of Ecuador 14 (6). Polypodiaceae-Asplenioideae. Dept of Botany, Göteborg University, Göteborg

Stolze RG, Pacheco L, Øllgaard B (1994) Flora of Ecuador 14. (5B). Polypodiaceae-DryopteridoideaePhysematieae. Dept of Botany, Göteborg University, Göteborg

SYSTAT (2004) SYSTAT 11. Systat Software Inc., San Jose

Tanner EVJ (1977) Four montane rain forests of Jamaica: a quantitative characterization of the floristics, the soils and the folira mineral levels, and a discussion of the interrelations. $J$ Ecol 65:883-918

Tanner EVJ, Vitousek PM, Cuevas E (1998) Experimental investigation of nutrient limitation of forest growth on wet tropical mountains. Ecology 79:10-22

Tryon RM (1986) Flora of Ecuador 12 A-13. Dicksoniaceae-Cyatheaceae. Dept of Botany, Göteborg University, Göteborg

Tryon RM, Stolze RG (1989-1994) Pteridophyta of Peru. Parts I-VI. Fieldiana, Bot 20:1-145; 22:1-128; 27:1-176; 29:1-80; 32:1-190; 34:1-123

Usher MB (1986) Wildlife conservation evaluation. Chapman and Hall, London

Walck JL, Baskin JM, Baskin CC (1999) Relative competitive abilities and growth characteristics of a narrowly endemic and a geographically widespread Solidago species (Asteraceae). Amer $J$ Bot 86:820-828

Wilcke W, Yasin S, Valarezo C, Zech W (2001) Nutrient budget of three microcatchments under tropical montane forest in Ecuador. Die Erde 132:61-74

Received: 1 August 2007 / Revised: 8 July 2009 / Accepted: 8 July 2009 